\title{
Re-Envisioning Pedagogy in the Lens of Asynchronous and Synchronous Learning in Higher Education Amid COVID 19 Pandemic in Kenya
}

\author{
Rosemary Khitieyi Imonje \\ Senior Lecturer, Curriculum Studies and Education in Emergencies \\ Faculty of Education, University of Nairobi, Nairobi, Kenya \\ E-mail: imonje@uonbi.ac.ke
}

Received: Sep. 7, $2021 \quad$ Accepted: Oct. 4, $2021 \quad$ Published: November 1, 2021

doi:10.5296/jse.v11i4.19097ＵRL: https://doi.org/10.5296/jse.v11i4.19097

\begin{abstract}
Higher Education institutions have faced many challenges since the onset of COVID 19 pandemic with closures that extended to more than three months. Coronavirus pandemic pushed universities to switch to online classes from the conventional traditional pedagogies. While the work to transition face-to-face instruction to online environments would mean a lot of technological preparedness among lecturers, students, infrastructure; these initiatives have at the same time lead to established familiarity with the necessary technological tools, and teaching approaches with online learning. Universities have taken up the initiative to re-plan, re- design and re-develop in-house capacity building structures and develop off campuses courses and distance learning in order to meet the diverse learning needs of the students and pedagogical needs of the faculty. Among these initiatives is re-envisioning pedagogy in the lens of asynchronous and synchronous learning in higher education amid COVID 19 Pandemic. This paper has analyzed reflections on asynchronous and synchronous pedagogies and learning during faculty capacity building sessions from the University of Nairobi, Kenya. Out of these reflections are recommendations that other universities in the global arena can apply for quality in the teaching-learning processes in institutions of higher learning.
\end{abstract}

Keywords: Pedagogy, Higher Education; COVID 19 Pandemic, Asynchronous, Synchronous, Blended Learning 


\section{Introduction}

The COVID - 19 pandemic, also referred to as the Coronavirus pandemic is an ongoing global pandemic and a health crisis caused by severe acute respiratory syndrome coronavirus 2 ( SARS-CoV-2) whose spread and impact on humanity has brought educational systems to a near-stand-still situation worldwide, leading to the widespread closures of schools and universities. The virus primarily spreads between people during contact via small droplets produced by coughing, sneezing and talking. Stadnytskyi et. al. (June 2020) has shown that speech-generated droplets may remain airborne for tens of minutes. People may also become infected by touching a contaminated surface and then touching their face. It is most contagious during the first three days after the onset of symptoms. According to UNESCO, on 1 April 2020, schools and higher education institutions (HEIs) were closed in 185 countries, affecting 1542412000 learners, which constitute $89.4 \%$ of total enrolled learners. At the beginning of May, some countries, experiencing decreasing numbers of cases and deaths, started lifting confinement measures. However, on 7 May (the time of writing the report), schools and higher education institutions (HEIs) were still closed in 177 countries, affecting 1268164088 learners, which constitute $72.4 \%$ of total enrolled learner

The guiding principles introduced by World Health Organization of social distancing, staying at home and the one meter apart; has become the bone of contention and dilemma for policy makers in reopening of educational institutions. This global lockdown of educational institutions is envisaged to cause huge interruption in student learning across the globe. Already most countries have cancelled internal and national public assessments for either end course or cohort, end year or end level skill based examinations. The formal conventional curriculum teaching, learning; and assessment frameworks have suddenly been converted into modes of online learning and platforms on an untested and unprecedented scale, with a lot of trial and error and uncertainty for everyone; and home schooling that is not only a massive shock to parents' productivity, but also to student's social life and learning. Policy guidelines in education are being revised on a go the second mile approach with everyone longing for COVID -19 pandemic to come to an end so that systems can be adjusted appropriately to the "new normal". Confinement and school closures have had unmeasurable consequences for leaners impacting on the achievement of SDG No.4; more so for learners in vulnerable and marginalized, magnifying already-existing disparities within the education system. In addition to the missed opportunities for learning, many students are subjected to economic and social stress. The world is working out on all technological possibilities to guarantee the right to education, universal and compulsory education; and that no child should be left behind during this contagious COVID 19 pandemic through which 8.986016 people are infected and 468908 people lost their lives(Global statistics on COVID, June 22, 2020).

Consequently, there is very limited information about the likely path of COVID -19 pandemic and when it may possible come to an end. Supposing it soars on for another one year, two years and so on; what then will become of learning and education? What will become of all students who are quarantined in their homes and other residences? That is why educationists need to come together to re-envision, re-focus and re-think education and learning more 
and more in public educational institutions in the midst of spread of and management of COVID -19 pandemic not only in Kenya but globally. We cannot plan only for today, but more so for tomorrow while applying lessons learnt from yesterday's experiences and research evidences on COVID-19 pandemic and beyond.

\section{Higher Education Progression in the Lens of COVID 19 Crisis Recovery}

Higher education has and is still struggling in its response mechanisms on the path to quality learning as a result of COVID 19 pandemic crisis closure disruptions. The question each one would ask themselves is; what happened to higher education systems in the past when crises happened? Analysis of the context, including disaster risk and pandemic analysis helps to ensure that education responses are appropriate, relevant; and strategies are re-designed on how higher institutions can build back better. Despite the availability of the traces of virtual technology that could mitigate the emergency crises such a Covid-19, the academic communities around the world were not well prepared to deal with such crises. Even though the adoption of virtual online learning had increased over the past two decades, the outbreak of the COVID-19 pandemic was responded to by the closure of schools and higher education establishments globally. In support of this, Giroux (2020) argued that COVID-19 pandemic was more than a medical crisis as it continues to inflict chaos and confusion in the global education system. As a result of the COVID-19 pandemic, in-person instruction was suspended and replaced with remote teaching technologies with millions of students/pupils taken out of the classroom due to the closure of institutions of higher learning.

One year into the COVID-19 pandemic, close to half the world's students in higher institutions of learning are still affected by partial or full school closures. There are great inequalities in access to educational opportunity, especially in public universities which have large student populations from marginalized, rural and remote slum regions where internet connectivity has never reached. On-campus programme management were and are still in limbo in most developing countries. Physical resources and facilities lost utility levels and are left to waste as students and faculty switch daily to online and virtual pedagogies and learning; from their remote learning spaces. The scheduled online/virtual learning programmes and spaces seem not to have been appropriately positioned across tertiary levels. Online and virtual faculty capacity building initiatives seem to lack harmonization and consistent coordination in most institutions of higher learning. Hence, prioritizing and re-envisioning higher education recovery is crucial to avoid a generational catastrophe.

In March 2021, UNESCO held a Global Education Coalition Meeting to take stock of lessons learnt, the greatest risks facing education today and strategies to leave no learner behind. This has provided space for policy dialogue to examine the most pressing current challenges, informed by the presentation of key data sets during COVID-19 crisis. Session 3 of this meeting was on digital transformation and the future of education: What are the key strategies for digital transformation of education systems? How can public-private partnership contribute to advancing the digital transformation during COVID-19 crisis? How has Covid-19 impacted the future of education? UNESCO Education Coalition with 175 members and more than 100 countries' engagement aim at transforming and re-imagining the education of the future, a 


\section{NI Macrothink}

Journal of Studies in Education

ISSN 2162-6952

2021, Vol. 11, No. 4

move that should be vibrantly aggressive in universities as a rock-bed of every nation's knowledge, skill, and education innovative research arena.

COVID 19 pandemic crisis school and college closures with a shift to online learning took toll on effective implementation of higher education hard skill based programs such as engineering and medicine. Online teaching and teaching within disciplines require experiential learning that equip future graduates with highly intellectual and professional skills to meet the demands of employers and the industry. The outbreak of COVID-19 however, shifted the academic community into new landscapes that require educators and students to adapt and manage their expectations. In a study by Ahmed and Opuku (2021) on Technology Supported Learning and Pedagogy in times of Crisis: the case of COVID 19 pandemic, among students from the College of Engineering at a Higher Education Institution in the United Arab Emirates (UAE), the findings revealed that technology supported learning tools are capable of enhancing students' experiential learning and associated competencies, however there were a number of pedagogical, technological and psychological challenges that faced students and instructors as a result of the sudden migration online, which are likely to play a role in the impediment of the students' learning cycle, due to the lack of preparedness in response to the state of emergency created by Covid-19. Despite these challenges, the study found that instructors with effective communication skills and teaching style, competent use of technology, flexible, friendly and supportive attitude towards teaching, played a positive role in mitigating for the lack of preparedness in response to sudden migration online due to COVID-19 pandemic. This study also revealed that by overcoming some of the technical challenges such as slow internet connection and interruptions, lessons learnt from the sudden migration to online delivery amid COVID-19, will help create new opportunities for the use of blended learning approaches to meet the needs of the ongoing COVID and future online deliveries. Most institutions of higher learning seems to be embracing the blended and asynchronous pedagogies as coping mechanisms for modes of delivery in the field of engineering and medicine which anchor on hard skill specializations. The asynchronous mode of delivery allows a convenient environment to the learner, which includes (but not limited to) online material such as; audio and video clips, communication through discussion board and email. With asynchronous mode the learners can work on their own pace and time of the day.

According to Kolb et al. (1984), the 1st stage of learning is concrete experience, whereby learning can happen either through a completely new experience or a reimagined experience that has already taken place. At this stage, each learner engages in an activity or task, while the key to learning is involvement. Hence, reading or watching is not sufficient to acquire new knowledge, and learners must actively engage in the set task. This stage is followed by reflective observation and this is when learners should step back to reflect on the task they engaged in. This stage in the learning cycle allows the learner to ask questions and discuss the experience with others and seek feedback. At this stage of the learning process, communication becomes vital, as it gives the opportunity to the learner to identify any discrepancies between their understanding of the gained knowledge and the experience itself. The 3rd stage is abstract conceptualization, at this stage the learner should try to make sense of the gained knowledge in order to draw conclusions from the gained experience by reflecting on their prior knowledge, 


\section{Al Macrothink}

Journal of Studies in Education

ISSN 2162-6952

2021, Vol. 11, No. 4

relating to ideas that they are familiar with, or discussing possible theories with peers. When learners, begin to classify concepts and form conclusions on the events that occurred, they move from reflective observation to abstract conceptualization, which entails interpreting their experience and making comparisons to their current understanding on the concept and modify their assumptions on already existing ideas. Finally, active experimentation is the stage that allows the learner to apply their knowledge in view of the gained experience by applying it into practice and showing its relevance to the exiting situation.

The most significant features of the experiential learning theory is that the direction learning takes is governed by learners' needs and goals. Learners seek experiences that are related to their goals, interpret them in light of their goals, and form concepts and test the implications of these concepts that are relevant to these needs and goals. Kolb et al. (1984) argues that, learners can enter the learning process at any stage of the learning cycle, they should really complete the entire cycle for the full learning to take place, and although all of these stages work together, some learners may prefer some components of the learning process over others which is dependent on the learners' learning style; thus most students will be enthusiastic to enter into learning if the pedagogy applied is in favor of their preference. In re-envisioning the designing of higher education curricular and pedagogy, learner -centeredness and preferences should be prioritized to attract more entry, enrolment, retention and completion of courses by students. In spite of this prioritization, student preferences may be infringed upon in less developed and developing countries where there are scarce or no resources and capacities for effective implementation of asynchronous, blended and other modes of delivery in higher education, especially during crises such as COVID,19 pandemic. However, in re-envisioning education and curriculum processes in higher education, partnerships and collaborative efforts and initiatives should be embraced in order to boost resource mobilization.

Globally, there have been initiatives that were never there before COVID pandemic to revitalize education amid current COVID 19 crisis, especially at elementary school levels. All these initiatives are pursued to ensure continuity in learning. For instance, Common Sense launched several initiatives with partners including Wide Open School, a free destination for families and educators that debuted in March 2020 in response to the COVID-19 pandemic and the ensuing United States of America nationwide shift to distance learning. The Wide Open School site is designed to supplement distance learning, support working parents with daily structure and a suggested schedule of activities for their kids at home, and present a diverse set of offerings that will appeal to every kid, from preschool through high school. Common Sense has also made their resources available to teachers and students in the United Kingdom of Great Britain and Northern Ireland in 2021. Little of these initiatives seem to reach out to higher education links.

As part of the GPE-funded consortium, UNESCO, in partnership with the South-East Asian Ministers of Education Organization (SEAMEO), a member of the GEC, are undertaking activities to create an online, multilingual regional teacher training course that will develop teacher capacity to adequately support children with disabilities. The online teacher training course will be adopted and piloted in Afghanistan, Bangladesh, Bhutan, Cambodia, Lao PDR, Myanmar, Nepal, Pakistan, and Timor Leste. Based on the module prototype, a script for 


\section{Al Macrothink}

supplementary audio/video resources is being developed, as well as new calls for proposals for the creation of accessible reading materials for children with disabilities.

ProFuturo strengthened its support and training to teachers, who during the pandemic became critical for the resilience of the education system. In partnership with Empieza por Educar, Teach for Liberia, Teach for Nigeria and former Teach for Tanzania, all members of the international Teach for All network, ProFuturo implemented a teacher professional development project that trained over 15,000 teachers in the three African countries. While schools were closed in the different countries, the trainers accompanied and trained the teachers virtually through Google Classroom, WhatsApp, videoconferencing and sharing interactive presentations, videos, podcasts and workbooks. When schools reopened, the on-site trainings returned with corresponding safety measures and social distances. Combining the on-site and online elements created a critical mass of trained teachers, and the programme is preparing for the next year with new countries to scale up the impact and apply lessons learned. Such capacity building initiatives have been taken up by institutions of higher learning, although there is need for further re-envisioning in these initiatives due to diversity of programs, pedagogies and curricular in higher education.

To better understand how the pandemic is affecting Africa's knowledge production centres, Mawazo Institute Women Leading Research in Africa, May, 2020, conducted a survey on 501 individuals in affiliated with higher education and research institutions across the continent. The respondents were students, academics, researchers, and others in the higher education sector. $69 \%$ of respondents were based in East Africa, almost $20 \%$ in West Africa, $8 \%$ in Southern Africa and another 3\% either in Central or North Africa, or outside of the continent. The results of the survey revealed a fractured system, exacerbated by a global pandemic. While $83 \%$ of respondents reported experiencing disruption to their ongoing learning, only $39 \%$ said they were enrolled in institutions offering e-learning options. The large number of respondents experiencing course interruptions highlights the need for greater investment in online learning With little known about how long the pandemic is expected to affect the region, this presents a critical gap for continued learning for students in that region. It should be noted that the e-learning trend across the continent is not homogeneous, and there are disparities in access to e-learning based on a respondent's gender and age. Only 17\% of West African respondents reported being at institutions with e-learning; options, compared to $43 \%$ of East African respondents and $41 \%$ of respondents in Southern Africa, suggesting there are many similar issues plaguing the continent. But the specific regional nuances are key in considering how to resolve these issues. The study surveyed respondents who had been engaged in research activities before the pandemic, 73\% reported a suspension of their lab or field research activities as a result of COVID-19. Depending on how long restrictions on research activities are kept in place, as well as downstream impacts on research funding and the broader higher education sector, this could have a significant negative impact on the already low research productivity in the region. Consequently, re-envisioning of pedagogy and learning designs eagerly required in higher education. 


\section{Literature Review}

In order to understand the disruption caused by COVID-19 on higher education and to investigate the first measures undertaken by higher education institutions around the world to respond to the crisis, the International Association of Universities (IAU) decided to launch the IAU Global Survey on the impact of COVID-19 on higher education around the world. It was available online and open from 25 March until 17 April 2020. Four regions participated in the survey, Africa, Americas, Asia and Pacific; and Europe. There are key findings that point to the need for re envisioning higher education beyond COVID -19 in Kenya. At almost all Higher Education Institutions (HEIs), COVID-19 affected teaching and learning, with two-thirds of them reporting that classroom teaching has been replaced by distance teaching and learning. The shift from face-to-face to distance teaching did not come without challenges, the main ones being access to technical infrastructure, competences and pedagogies for distance learning and the requirements of specific fields of study. At the same time, the forced move to distance teaching and learning offers important opportunities to propose more flexible learning possibilities, explore blended or hybrid learning and to mix synchronous learning with asynchronous learning. At the same time, 60\% of HEIs also reported that COVID-19 has increased virtual mobility and/or collaborative online learning as alternatives to physical student mobility. Almost $80 \%$ of respondents believe that COVID-19 will have an impact on the enrolment numbers for the new academic year. Almost half (46\%) believe that the impact will affect both international and local students.

\section{Contextualization of Issues, Controversies and Recommendations}

Education is now more than ever in an emergency high intensity state worldwide. Expressing the "New normal or rather a state of Normalcy" as the second, third and on-going phases of the spread and impact of COVID 19 pandemic on humanity with high implications on education; does not effectively apply and make sense in this SARS - CoV-2 crisis or emergency. Such a state of emergency need radical thinking, re-envisioning of feed - forward next steps to quality education. Quality education in emergency is education that is available, accessible, acceptable and adaptable. This can be achieved through refocussing the principles of participation, accountability, non-discrimination and legal protection. The open question to each one is "What does higher education look like in practice amid COVID -19 pandemic and beyond?" It may be probably true that higher education skill, content, pedagogy and resource gaps in relation to access, delivery, transition and completion; are more visible during this COVID 19 crisis than before. What then are the critical gaps that need to be re-envisioned to build stronger, resilient content-skill-resource - pedagogy structures for higher education beyond COVID -19 pandemic?

In re-envisioning learning beyond COVID -19 pandemic, Higher education takes a significant lead. In this paper reference will be made to universities to represent other institutions of higher learning. Generalization can be made in reference to other institutions of higher learning but specific examples will be drawn from the University of Nairobi. There are several questions that every university needs to respond to in this era of COVID -19 Pandemic as follows: 
- What is the "changing" core mandate of the university and how is it related to their response to COVID 19 crisis in their area of jurisdiction?

- Which coping mechanisms have been applied to ensure sustained learning continuity and increase in student completion and graduation rate, during and after COVID 19 pandemics? What is the measure of success to sustainability of these mechanisms?

- What strategies can be put in place to advocate, collect data; and build and share knowledge, to strengthen the resilience of higher education and learning systems in re-envisioning the future?

- How can digital learning, including online platforms, education resources, digitized curricula and assessments be re-envisioned to strengthen inclusive pedagogies, outreach approaches and modes of learning; ensure marginalized contexts and disadvantaged groups and students with special needs are considered in design patterns, so that no student is left behind in times of crisis and recovery processes?

- How can universities re-envision partnerships and collaborations with donors, multilateral organizations, the private sector, non-profits, civil society, local communities and stakeholders, networks and associations to strengthen continued higher education learning capacities and innovativeness?

The key realization in responding to the concerns in the above three questions is that higher education has not been totally exempted from the closures and lock downs caused by the spread of COVID -19 Pandemic; in spite of the fact that it has to ensure equity and inclusion in access to quality education and lifelong learning for all, in line with the fourth Sustainable Development Goal (SDG 4), leaving no one behind. Nearly $90 \%$ of university faculty are working from home. The other $10 \%$ of the faculty are those in essential services who must report on duty. Already there are crucial departments and schools in various public universities that have remained closed because of the nature of the courses they offer. For instance; college of biological and physical sciences, Architecture, engineering, to name but a few; whose practical applications cannot be taught effectively through online modes and platforms. Massive numbers of student population studying at the universities originate from different social, economic and regional (geographical) backgrounds; which cannot be ignored. Such diversities pause a challenge to access, delivery, retention, completion and governance of quality university education in the most needed societal skill areas.

With the outbreak of COVID -19 pandemic, universities have a big role to play in ensuring continued teaching, learning, research and community service guided by core values of innovativeness; leadership culture that is people - focused and responsive to internal and external clientele. Universities have a responsibility to assist the society to overcome the challenges brought about by the effects of this pandemic. Most universities have created a pool of professionals, experts and researchers from the university manpower who have been connected through the mandate of their institutions to contribute to development and implementation of rapid responses to curb the socio -economic and health impact of the pandemic at the national, county and local levels. The concern is how these findings and 


\section{Al Macrothink}

initiatives out of these researches and individual consultancy linkages can be used to re envision practical solutions towards COVID 19 Pandemic. Initially, findings and results out of key researches have been left in print form on the shelves of various institutions and offices, never to be disseminated, coordinated and implemented. Re- envisioning of such efforts will lead to constructive follow up measures that will build strong resilient communities that are proactive in times of crisis beyond COVID -19 pandemic. The key to this is utilization and monitoring of evidence from result based initiatives.

During this era of COVID 19, many universities have come up with different measures drawn from existing intellectual resources to ensure continued in learning, teaching, research and community outreach. The University of Nairobi developed an interactive intellectual linkage and networking between university governance, faculty and students which has established a sustainable communication loop and strategy. In the first month of educational institutional closures, there were information, communication and technology staff orientations and plan of action. Through this initiative; trainings of online skills that targeted, academic staff, administrative and support staff; and students have been undertaken. The university has trained over $92 \%$ of faculty, $95 \%$ of key support staff on the use of online teaching and learning tools. Over $70 \%$ of students have been oriented on how to use these online tools for academic progression. The University Senate resolved to use the following online platforms; Zoom, Google Classroom, Big Blue Button, Blackboard, Webex, University e-learning platform (e-class); in transitioning all teaching and learning to online platforms in the face of Covid-19 pandemic. The faculty was well advised on modes of delivery while using these platforms. That some of these platforms limit the numbers per session and therefore may require the lecturer to group students into small groups for larger classes. For the sake of students who may have challenges to connect for some reasons, including timing of the lecture, it would be appropriate to record the sessions and share with them via email or WhatsApp. These guidelines have given faculty confidence to manage their lessons online, ensuring continuity in most programs. Another coping mechanism that has consistently helped both the faculty and students is the linkage of University of Nairobi with Mobile service providers; Telkom and Safaricom; to provide bundles continuously for online subscriptions. These has helped the university community to organize and manage online capacity building workshops, online teaching - learning processes; online examination procedures. These are innovative best practices that need appropriate monitoring and follow up measures to adjust to emerging issues and sustainability modes during and after COVID -19 pandemic.

Online assessment procedures and formats in most universities have posed a challenge. The closure of institutions of higher learning for COVID 19 pandemic got most departments which were about to administer semester exams off guard. Some students were to have their end of cohort final examinations which could lead into graduation. Although most of the academic staff have been trained on online structuring of examination through e class and Moodle platforms, it will take time and much consistent practice to structure examinations for large student populations as it is in most cohort. That is a challenge that most universities are facing. Many universities and colleges are replacing traditional examinations with online 


\section{Al Macrothink}

Journal of Studies in Education

ISSN 2162-6952

2021, Vol. 11, No. 4

assessment tools. This is a new area for both faculty and students - who are, but fumbling to catch up with the online teaching and assessment skills; and thus online modes of assessments are more likely to have larger measurement error than usual. Research shows that employers use educational credentials such as degree classifications and grade point averages to sort applicants (Piopiunik et al. 2020). The increase in applicants' signals will reduce the matching efficiency for new graduates out of COVID 19 onlime assessment crisis on the labour market, who might experience slower earnings growth and higher job separation rates. This is costly both to the individual and also to society as a whole (Fredriksson et al. 2018). For new graduates emerging out of COVD-19 pandemic crisis assessment systems, what type of policies should support their entry to the labour market to avoid longer unemployment periods? This is a critical open question that should seek policy guidelines in envisioning process.

In spite of these challenges online programs in all institutions of higher learning have to be sustained with some integrated and blended measures that can ensure continued learning for minority groups of students with differentiated learning and those in most difficult and marginalized regions in order to ensure access to higher quality education for all. The ICT departments should continually apply open door policy in training and filling the gaps that arise in the course of the implementation of online teaching among faculty and students. This is due to the fact already discussed earlier; that there is very limited evidence on when COVID 19 pandemic is coming to an end.

\section{Faculty Reflections on Asynchronous and Synchronous learning}

This paper anchors on reflections made by the faculty at one of renowned world class universities anchored on scholarly excellence through creation, preservation, integration, transmission and utilization of knowledge research, the University of Nairobi, in Kenya. The university has a population of over 84000 students across its 326 academic programmes, 1500 academic faculty, and 1350 international collaborations and over 500 project staff. Since the Onset of COVID 19 Pandemic, and closure of educational institutions in the mid-March 2020 for Kenya, The University of Nairobi, closed physical structures as per the government health protocols, but opened virtual online learning spaces and platforms for continuing students and faculty. Total closure of the institution could be detrimental and pose dire wastage to continuity of the learning of her students. The University embarked on continuous and loaded online virtual capacity building of her staff on diverse online teaching and learning platforms as a way of equipping the staff with skills and knowledge on virtual pedagogies and learning styles. Some of the Online Platforms that the staff continue to be oriented on, include: Learning Management systems, google Meet, Microsoft teams, MOODLE, Zoom; among others. During one of the many faculty capacity building initiatives on Asynchronous Teaching and Learning at The University in September 2021, the staff were equipped with skills and required competencies for designing of content for asynchronous instructional delivery using a standardized structure; Integrating interactive elements in for content delivered by asynchronous delivery mode development; Incorporating quality assurance mechanisms for content development in asynchronous mode of delivery asynchronous teaching and learning; offering leaner support to students leaning through 


\section{Ml Macrothink}

asynchronous instructional delivery mode; Conducting assessments for content delivered using asynchronous instructional delivery mode; and Using appropriate ICT tools for development of content for asynchronous instructional delivery mode. Over 651 teaching staff (faculty) attended the five day course through Online Microsoft Teams tool. Among the facts discussed during the capacity building session, include;

- Online learning takes place partially or entirely over the internet. It encompasses a range of technologies such as the worldwide web, email, chat, audio and video conferencing delivered over computer networks to impart education

That online learning can be done asynchronously or synchronously or both to students in institutions of higher learning.

Synchronous learning is interactive, two-way online instruction that happens in real time with both the teacher and learner in the virtual classroom, as it is the case in video conferencing technologies like google meet, google hangouts, Microsoft Teams, Zoom, Live chatting, and Live-streamed lectures or demonstrations

Asynchronous learning occurs when students learn the same thing at different times from different places. Teaching materials are posted online such as on Learning Management system; learners access learning content; take assessments, and communicate at their own time and pace; communicating with each other and the teacher via discussion boards or forums, or even by email; the instructor, the learner, and other participants are not engaged in the learning process at the same time; and thus there is no real-time interaction with other students

When the faculty were asked on challenges that face higher education pedagogy during the synchronous and asynchronous learning sessions as drawn from their interactions with students during online teaching; they had the following reflections:

Asynchronous teaching and learning is limited in that it is not flexible with large classes where there is lack of personalized attention: requires strong internet connection

- Requires webcam and microphone, students and faculty in remote marginalized regions with no power and internet connectivity cannot log on, and poverty stricken students without appropriate gadgets will never attend lessons and engage in end of course assessment procedures.

The strengths of asynchronous learning include that fact that students can progress through the learning when they want, where they want, at the pace they want, in the order they want. Students have more time to reflect on what they learned. It is inclusive for all students who are accommodated in learning. Students can participate in the same activities regardless of time zone and learning environment and it is a more cost-effective than classroom teaching. 


\section{MIMstitute"}

Asynchronous lack of personal instructor attentiveness and interaction; requires learner's self-discipline and concentration: Self-pacing requires increased levels of self-direction; not every skill can be taught asynchronously or online in general; some students may struggle without constant guidance and interaction; not all instruction is best suited for self-paced learnings.

In both asynchronous and asynchronous pedagogy, there is inability to account for particular student participation in line with the requirement and university policy of $70 \%$ attendance for eligibility to take examinations.

In both asynchronous and asynchronous pedagogy, quality and accuracy of student examination results has been an effort in futility with engagement of students in final virtual examination malpractices and impersonation is on the increase in some institution of higher learning

\section{Recommendations}

Consequently, sustaining the "new normal" and raising the education curve in higher education is considered an on-going open point of analysis and discussion for all to engage including the lay public, Commission for University Education, Ministry of Education and all multi sectoral arms of governments, partners, donors and global community; if the integrity of higher education is to be upheld. It is more than getting the faculty and students ready to use online platforms. It is re-envisioning, refocusing and re - aligning the pedagogy structures and resources; infrastructure and programmes in higher education to be inclusive and reflective of emergency and beyond contexts - to manage an online emergency education. It includes;

- Re-focusing objectives of university education to include advancement of knowledge through teaching, scholarly research and scientific investigation, even in crisis, conflicts and pandemics

- Fostering of capacity for independent critical thinking not only among students but among faculty for preparedness, response and reconstruction in knowledge and skill application in all contexts of life.

Re-construction of curricular and programmes to reflect flexibility in coverage to suit such contexts as COVID -19 pandemic and beyond

Re thinking and focusing assessment tools and flexible examination formats that can survive and be resilient to severe crisis content

- refocus mobilization of resources and strategies through inter linkages for all context responses

- Re thinking pedagogical approaches to include more flexible learning possibilities, explore blended or hybrid learning and to mix synchronous learning with asynchronous learning to accommodate learning in difficult conditions and circumstances and cannot access quality higher education. 


\section{Al Macrothink}

Critically thinking, the above proposals could be within the policy guidelines and documents but how much of it is brought into existing implementation processes so that familiarization with them is not the any new normal coming up in crisis times. That is why re envisioning is important so that existing knowledge can be reviewed and refocused. For example when dealing with interpretation of what an academic programme means from point of view of the legal frameworks; academic programme refers to the design of learning content which includes the intention, the structures of the content, the delivery mode, academic resources and assessment modes. The assumption in this interpretation is that "all academic programs are developed and implemented within a stipulated time or duration framework; which was and is right, when there is no soaring crisis or pandemic such as COVID -19 pandemic. However, when pandemics such as COVID 19 strikes; all program time frameworks go beyond the coping mechanisms of existing structures. Thus, it becomes necessary to include the clause on crisis while re-envisioning the interpretation of what an academic university program means. This will guide reconstruction of curriculum or program reviews, content delivery and assessment modes at higher education to include pandemic or crisis contexts. It may not be surprising that some institutions of higher learning may not be having interpretation and context of what "an academic programme" means in their charters which may compromise the institutional mandate definition.

\section{Conclusion}

In conclusion, higher education links and produces graduates who contribute to the social, economic, technological, scientific and political developments for any nation. It is clear that the future of higher education priorities needs re-thinking and contextualization for coping mechanisms to recovery during crises. International and multilateral cooperation within the higher education sector along with policymakers, communities and other stakeholders needs to be strengthened for quality interventions in learning processes. There is need for knowledge creation and dissemination to build a sustainable future. There is need to review and re- envision university mission and philosophy; program monitoring, evaluation and accountability; and learning delivery systems from the traditional and conventional thinking to adjust to changing emergency and crisis contexts. Most of the higher education philosophical and mission guidelines connect to national goals; patriotism; moral responsibility; building of strong resilient value and aspiration systems of the country and global community. Higher institutions of learning articulate these mandate through creation, preservation, transmission and utilization of knowledge. Consequently these will lead into an optimal difference in performance and implementation when institutions of higher education are the ones taking the lead in providing practical applicable interventions during and beyond COVID 19 Pandemic.

\section{References}

Ahmed, V. and Opuku, A. (2021). Technology Supported Learning and Pedagogy in times of Crisis: the case of COVID 19 pandemic. Springer, Education and Information Technologies. https://doi.org/10.1007/s10639-021-10706-w

Fredriksson, P, L Hensvik, and O Nordström Skans. (2018). Mismatch of Talent: Evidence on 


\section{Macrothink}

Match Quality, Entry Wages, and Job Mobility. American Economic Review, 108(11), 3303-38. https://doi.org/10.1257/aer.20160848

Giroux, H. A. (2020). The COVID-19 pandemic is exposing the plague of neoliberalism. Truthout, 7 April. https://doi.org/10.4324/9781003154587-1

Hillman, T., Bergviken Rensfeldt, A., \& Ivarsson, J. (2020). Brave new platforms: a possible platform future for highly decentralised schooling. Learning, Media and Technology, 45(1), 7-16. Hodges, C., Moore, S., Lockee, B., Trust, T., \& Bond, A. (2020). The diference between emergency remote teaching and online learning. EDUCAUSE Review. https://doi.org/10.1080/17439884.2020.1683748

Howard, S. K., Tondeur, J., Siddiq, F., \& Scherer, R. (2020). Ready, set, go! Profling teachers' readiness for online teaching in secondary education. Technology, Pedagogy and Education. https://doi.org/10.1080/1475939X.2020.1839543

Impact of COVID 19 on Higher Education around the World: International Association of Universities (IAU) Global Survey Report; ISBN: 978-92-9002-212-1. Paris. France. May 2020

Kolb, D. A., Rubin, I., \& McIntyre, J. M. (1984). Englewood Clifs Organisational psychology: An experiential approach to organisational behavior. Prentice Hall.

Learning to Realize Education's Promise: World Bank Development Report 2018

Mawazo Institute. (May, 2020). Impact of COVID -19 on Africa's Higher Education System, Nairobi, Kenya

Piopiunik, M, G Schwerdt, L Simon and L Woessman. (2020). Skills, signals, and employability: An experimental investigation. European Economic Review, 123, 103374. https://doi.org/10.1016/j.euroecorev.2020.103374

Rangvid, B S. (2015). Systematic differences across evaluation schemes and educational choice. Economics of Education Review, 48, 41-55. https://doi.org/10.1016/j.econedurev.2015.05.003

Republic of Kenya; The Universities Act. No. 42, 2012

UNESCO. (2021). Supporting Learning Recovery One year into COVID-19. The Global Education Coalition in Action. March 2021,Published in 2021 by the United Nations Educational, Scientific and Cultural Organization, 7, place de Fontenoy, 75352 Paris 07 SP, France 